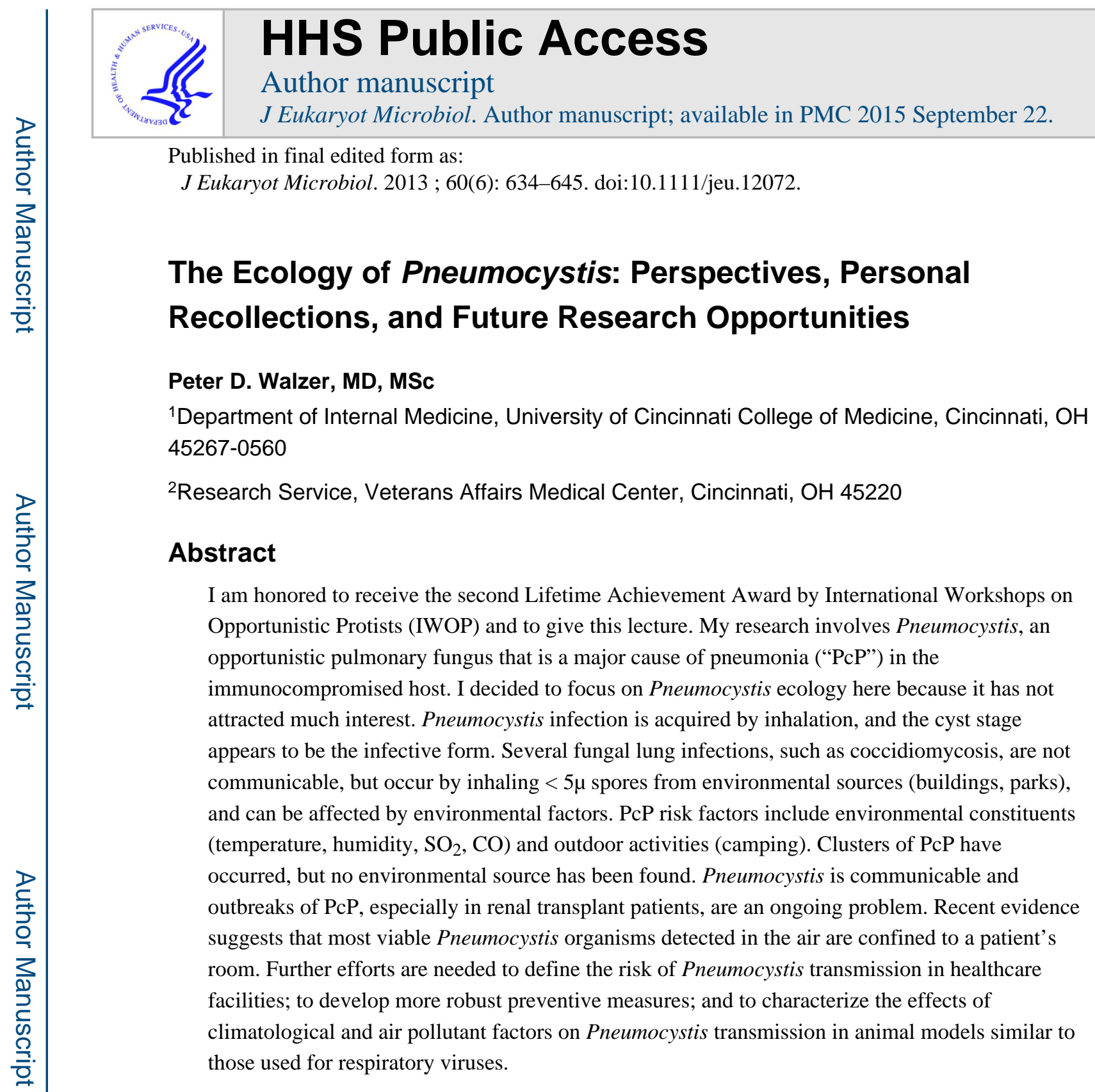

\title{
Keywords
}

Pneumocystis; ecology; fungi; climate; air pollution; contagion; reflections; research opportunities

\begin{abstract}
PNEUMOCYSTIS was discovered by Chagas in 1909 who mistakenly thought that the organism was a new stage in the life cycle of Trypanosoma cruzi (Chagas 1909). However, further work by Carini and the Delanöes established that the organism was a new genus and species, and was named Pneumocystis carinii in 1912 (Delanoe and Delanoe 1912). For many years, Pneumocystis was considered to be a protozoan of little medical importance found in the lungs of humans and animals in nature. The first demonstration of the clinical importance of Pneumocystis occurred when it was found to be the cause of interstitial
\end{abstract}

\footnotetext{
Correspondence: Peter D. Walzer, Emeritus Professor of Medicine, Division of Infectious Diseases, Department of Internal Medicine, University of Cincinnati College of Medicine, 231 Albert Sabin Way, Cincinnati, OH, 45267-0560, Telephone: 513-558-4704, peter.walzer@uc.edu.
} 
plasma cell pneumonia, a new disease that occurred in outbreaks in premature and malnourished infants in crowded European orphanages during and after World War II (Gadjusek 1957). Pneumocystis came to prominence again in the 1960s and 1970s when it was found to be an important cause of life-threatening pneumonia (termed "Pneumocystis pneumonia" or "PcP") in young children with primary immunodeficiency disorders and in children and adults of all ages who were receiving immunosuppressive agents for the treatment of cancer, organ transplantation, and other disorders (Walzer et al. 1974).

The discovery of AIDS in the early 1980s added a new chapter because PcP was the most common clinical manifestation of this new disease (Masur et al. 1981). The sheer number of cases of PcP dramatically increased the importance of this organism in the medical community. The increased incidence of $\mathrm{PcP}$ was accompanied by a rise in infections caused by other opportunistic protists such as Toxoplasma gondii, Cryptosporidium spp., and the Microsporidia, and attracted new investigators to this emerging field of research. It soon became apparent that existing scientific meetings did not provide the intimate setting for investigators who studied these organisms to meet, share information, and develop collaborations. To address this need, the International Society of Protozoologists established the first International Workshop for Opportunistic Protists (IWOP) that was held in Bristol, England in 1988. The meeting was particularly notable because molecular evidence establishing Pneumocystis as a fungus rather than a protozoan was presented for the first time (Edman et al. 1988, Stringer et al. 1989).

Since then, IWOP has met about every two years alternating between North America and Europe. The most recent meeting, the $12^{\text {th }}$ IWOP was held in Tarrytown, NY in August 2012. These meetings have heralded the unfolding research directions in the field; have served as a point of discussion for controversial issues such as nomenclature; and have been of tremendous benefit to the maturation of this nascent field of research over the decades. I was truly honored to be chosen by the IWOP organizing committee to receive the second Lifetime Achievement Award for my many years of research on Pneumocystis; to give the plenary lecture; and to prepare this article.

In considering topics for the theme of the article, I decided to focus on Pneumocystis ecology: the interaction of the organism with its environment and/or other microbes. The ecology of Pneumocystis has not attracted much investigative interest, as suggested by the fact that my PubMed search using "Pneumocystis" and "ecology" resulted in only eight articles. This statement is obviously an oversimplification because there have been many studies that have included some aspects of ecology; yet, I think it is fair to say that not much attention has been devoted to the concept of Pneumocystis ecology per se.

What factors might have contributed to the above situation? First, despite many years of effort by multiple investigators, there is still no reliable in vitro Pneumocystis cultivation system. Thus, the major tools for Pneumocystis research have been animal models and molecular techniques. Second, it has long been known that Pneumocystis organisms found in humans and animals are morphologically similar; yet, it has taken a long time to prove that these organisms are genetically distinct and host-specific (Redhead et al. 2006). These issues must be taken into consideration when comparing Pneumocystis organisms obtained 
from different hosts. Third, since Pneumocystis only causes serious disease in the immunocompromised host, some of its clever tools to avoid host defenses have been underestimated. Pneumocystis has proven to be a formidable opponent that has exhibited both tenacity and high adaptability, qualities that are essential to interaction with its host and environment (Cushion 2010).

In this article, I have focused on aspects of Pneumocystis ecology that are clinically, epidemiologically, and/or biologically important; that can be learned by studying the ecology of other related respiratory pathogens; and by non-infectious environmental conditions that affect the respiratory tract. Since I have been involved in Pneumocystis research for over 40 years and been involved directly or indirectly in many of these events, I have included personal observations of some of these events and their impact on Pneumocystis ecology. Finally, I conclude with some recommendations for new areas of Pneumocystis research that are needed to advance our knowledge of the organism's ecology.

\section{PNEUMOCYSTIS ECOLOGY}

\section{General Features of Pneumocystis}

Members of the genus Pneumocystis are extracellular fungi of normally low virulence that reside in the lungs of humans and animals. Unlike most other fungi, Pneumocystis spp. have adapted to individual mammalian species. $P$. carinii and $P$. wakefieldiae are both found in rats; P. murina in mice; $P$. oryctolagi in rabbits, and $P$. jirovecii in humans (Cushion 2010). These species are those that have been formally defined, and it is expected that every mammalian species has its own Pneumocystis spp. Such host specificity indicates a coevolution of the fungus with its mammalian host. Infection with Pneumocystis is acquired by inhalation, and this first occurs early in life. In most cases, this infection is asymptomatic or manifested as a mild respiratory infection (Larsen et al. 2007, Vargas et al. 2001).

Serological studies have shown that most (about 80\%) children have developed serum antibodies to the organism (Vargas et al. 2001, Djawe et al. 2010a).

According to current concepts, the life cycle of Pneumocystis is composed of asexual and

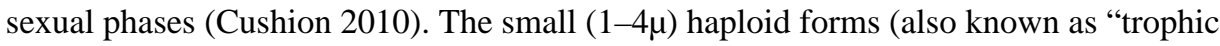
forms" or "spores") replicate asexually by binary fission. In the sexual phase, two trophic forms mate and ultimately develop into a mature $(5-8 \mu)$ "cyst" or "ascus" with eight nuclei. The nuclei develop into trophic forms or spores which are released with excystation and begin the life cycle again. The cyst has a thick cell wall rich in $\beta-1,3$ glucan and other carbohydrates. There has long been speculation about the infective form of Pneumocystis (Cushion et al. 2010). However, recent PcP prophylaxis and treatment studies in immunosuppressed mice and rats using echinocandins, which are $\beta-1,3$ glucan synthase inhibitors, have shown that the cyst is the infective form of Pneumocystis (Cushion et al. 2010). Treatment with the echinocandin, anidulafungin, markedly reduced the number of cyst forms, but left the number of trophic forms intact; upon withdrawal of anidulafungin, the number of cysts returned to pre-treatment levels. Most importantly, treatment with anidulafungin prevented transmission of Pneumocystis infection. 
After inhalation, Pneumocystis cysts have been thought to make their way to the alveoli and release 8 spores that develop into trophic forms, which adhere to Type 1 alveolar lining cells (Walzer and Smulian 2010). As the host becomes more immune suppressed, Pneumocystis multiplies slowly and gradually fills the alveoli. The incubation period for PcP is about 4 to 8 weeks.

Over the past decade, it has been well-established that after inhalation, the interaction of Pneumocystis is more complicated. Pneumocystis often colonizes the respiratory tract of animals and humans (Morris and Norris 2012). Risk factors for colonization include chronic lung diseases, especially COPD; cigarette smoking; geography; pregnancy; young children with respiratory symptoms; HIV, decreased CD4+ cell count, cancer, organ transplantation, and autoimmune diseases; lack of PcP prophylaxis; and immune suppressive drugs such as corticosteroids and TNF-a inhibitors (Morris and Norris 2012).

The relationship of Pneumocystis colonization to the development of fulminate pneumonia is poorly understood. In some cases, colonization was followed by PcP that was caused by the same strain. However, in other cases, PcP develops without colonization or the strain that causes PcP differs from the colonizing strain (Morris and Norris 2012). Individuals colonized with Pneumocystis can transmit the infection to others.

Several studies in human populations and animal models have shown that Pneumocystis colonization alone, or in combination with smoking and other factors such as HIV infection, is also a risk factor for the development and/or worsening of COPD (Morris and Norris, 2012). Perhaps the most compelling studies have been performed in primates infected with the simian form of HIV (SHIV). Naïve SHIV+ primates co-housed with a Pneumocystisinfected SHIV+ primate became colonized with Pneumocystis and developed progressive functional and anatomic airway obstructive disease consistent with COPD; by contrast controls (SHIV+ primates not exposed to Pneumocystis) did not (Shipley et al. 2010).

An intriguing report examined the dynamics and patterns of Pneumocystis colonization of two species of rat-associated Pneumocystis ( $P$. carinii and $P$. wafieldiae) in a rat colony over a 6 year period and 700 generations (Icenhour et al. 2001). The Loktka-Volterra competition model predicted competitive exclusion of one species, but co-existence was found in 460 replicate populations. $P$. carinii was associated with higher humidity and higher organism burden, whereas $P$. wakefieldiae was associated with lower temperature and higher rat census. Thus, $P$. carini and $P$. wakefieldiae were in competitive co-existence influenced at least partly by extrinsic factors.

\section{Pneumocystis Antigens and Host Evasion}

Although Pneumocystis is of low virulence, the organism is tenacious, resourceful, and difficult to eradicate. One common mechanism by which microbes evade their host is by antigenic variation; this is vividly demonstrated by trypanosomes, which develop a variant surface antigen during infection that is not recognized by the host (Rudenko 2011). Similar to the trypanosomes, Pneumocystis has a major surface glycoprotein (Msg) which actually represents a family of related glycoproteins encoded by about 50-80 genes depending on the species (Keely and Stringer 2009, Stringer 2007). Msg also contains protective B and T-cell 
epitopes, and plays a central role in the interaction of the organism with the host (Gigliotti and Hughes 1988, Theus et al. 1995, Theus et al. 1998, Walzer 1999). However, since Pneumocystis cannot be reliably cultivated in vitro, indirect methods of demonstrating this evasion have been used.

In one study, mice recovering from PcP developed a vigorous systemic antibody response to Msg, but there was little or no local antibody response from draining lymph nodes to Msg (Gigliotti et al. 1998). Another report showed that mice immunized with crude or recombinant Pneumocystis antigens developed serum antibodies to both types of antigens, suggesting that the antibodies were cross reactive; however, the immunized mice only developed a proliferative response to the specific immunizing antigen preparation (Bishop et al. 2012). Similar results were also found in small numbers of humans. The authors concluded that antigenic variation and evasion of the host immune response in this model occur at the cellular immune response rather than the humoral immune level (Bishop et al. 2012). These findings might explain why our group and other groups of investigators have encountered such difficulty in eliciting proliferative immune response to recombinant forms of Msg (P. Walzer, unpub. data).

\section{Environmental Factors and Airborne Transmission of Microbes}

Once Pneumocystis or any infectious agent leaves its source, there are important environmental factors that affect its survival in air and thus the success of transmission to its human or animal host. These factors can be divided into two broad categories: (1) Climatological Factors, which include temperature, humidity, precipitation, wind speed, atmospheric pressure, and day-light cycle; and (2) Air Pollution Factors, which include ozone, carbon monoxide $(\mathrm{CO})$, sulfur dioxide $\left(\mathrm{SO}_{2}\right)$, nitrogen dioxide $\left(\mathrm{NO}_{2}\right)$, and particulate matter (Sloan et al. 2011, Greer et al. 2008, Tang 2009, Eames et al. 2009).

The effects of environmental factors on airborne survival transmission are tempered by the type of organism and its properties (Tang 2009, Eames et al. 2009). Viral components include the presence or absence of lipid envelope, type of virus (RNA or DNA), and presence or absence of host material (e.g. saliva). Bacterial components include outer coat (e.g. gram positive cocci peptidoglycan, gram negative lipopolysaccharide). Organism survival is also more sensitive to methodology (e.g. collection, culture) and data analysis is more complex.

\section{Environmental Factors and Fungal Lung Infections}

Fungal lung infections, which are not contagious, are acquired by spores $<5 \mu$ in size from an environmental source such as buildings, parks, and gardens. Weather factors such as wind speed are also important. Fungal spores are hardier than other organisms and can travel long distances in the air. A recent study has examined the effects of climate change on deep mycoses and proposed a "biogeoclimate hypothesis" for the interaction of climate and fungal life cycles that involves three different stages: (i) precipitation and soil moisture that enhance fungal growth; (ii) a dry period that enhances the development of spores; and (iii) wind and other disturbances that disperse the spores, which are then inhaled by people (Panackal 2011). These changes have been perhaps most vividly demonstrated in the "blow 
and grow" hypothesis applied to seasonal fluctuations in the life cycle of coccidiomycosis (Tamerius and Comrie 2011). Cocciodioides imitis exists in nature (mainly in Southwestern USA) as a mold with septate hyphae; the hyphae split off into small $(<5 \mu)$ arthroconidia that are aerosolized and then inhaled by humans. Within the lung, the arthroconidia develop into spherules that develop into endospores that again become spherules and repeat the host cycle.

Blastomycosis is another fungal infection that illustrates how environmental factors may influence the occurrence and/or clinical manifestations of the deep mycoses. Blastomyces dermatidis exists in its natural habitat (mainly in the Midwest and southern parts of the USA, including US and Canadian areas that border the Great Lakes) as a mold with septate hyphae. The hyphae produce conidial spores that can become airborne and be inhaled or inoculated into the skin of humans. Once acquired, the spores develop into budding yeasts and can replicate in the lung or spread to many deep organs of the body. Studies have shown that there is a seasonal variation in human and canine cases of blastomycosis. In humans, seasonal factors are related to clinical presentation: localized pneumonia, which likely represents recently acquired infection, occurred mainly in the fall; diffuse lung disease or disseminated blastomycosis, which probably represents reactivation, occurred mainly in the spring (Light et al. 2008).

Invasive aspergillosis illustrates the effects of both geography and climate on the occurrence of this disease (Peláez et al. 2012, Chang et al. 2008, Panackal et al. 2010). Members of Aspergillus sp. are ubiquitous in the environment, and infection is acquired by airborne conidia. Invasive aspergillosis mainly afflicts immune compromised patients such as hematopoietic stem cell transplant recipients and has a high mortality rate. Nosocomial outbreaks of aspergillosis in these patients have been associated with construction either inside or outside the hospital; thus, measures such as air sampling and the use of HEPA filters help control or prevent these infections (Chang et al. 2008). A recent study compared the occurrence of invasive aspergillosis in Seattle, WA and Houston, TX over a ten-year period (Chang et al. 2008). In Seattle, the highest incidence of aspergillosis was in the summer and correlated with increased spore counts and decreased precipitation (Panackal et al. 2010). By contrast, in Houston, the aspergillosis incidence, spore counts, and precipitation exhibited no seasonal changes.

\section{Environmental Sources of Pneumocystis}

Since Pneumocystis is a fungus that causes lung infections, several reports have raised the possibility of environmental sources of the organism. Pneumocystis DNA has been found in pond water and in the air (Casanova-Cardiel and Leibowitz 1997, Kaneshiro and Maiorano 1996, Olsson et al. 1998, Wakefield 1996). A CDC study of risk factors for community acquired pneumonia in $\mathrm{HV}+$ patients found that outdoor activities (e.g. hiking, camping, gardening) were independent risk factors for PcP (Navin et al. 2000). Yet, no definitive evidence of an environmental source of $P$. jirovecii in any of these studies was found.

Geographic clustering of PcP in HIV+ patients has been found in Cincinnati, OH and San Francisco, CA (Dohn et al. 2000, Morris et al. 2000). Cases of PcP were mainly found in the more affluent areas of these cities where there is more green space. These clusters suggested 
the possibility of exposure to a common source of Pneumocystis. This source could be an environmental source as has occurred with outbreaks of other fungal infections such as histoplasmosis (Centers for Disease Control and Prevention 2012). Unfortunately, no studies of environmental sources of $P$. jirovecii in these clusters were performed. The source could be a single person with $\mathrm{PcP}$ who then transmitted the infection to other HIV patients. Alternatively, the clusters could have occurred if there were places where the HIV+ individuals liked to meet or congregate. One outbreak of PcP occurred in renal transplant patients who shared waiting and treatment rooms (Chave et al. 1992). However, there was nothing in the analysis of the two clusters that pointed to person-to-person transmission.

\section{Environmental Factors and PcP}

The role of environmental factors on the occurrence of PcP in humans (mainly HIV+ patients) has attracted considerable investigative interest (Hoover et al. 1991, Miller et al. 1992, Lubis et al. 2003, Varela et al. 2004, Miller et al. 2007, Miller et al. 2010, Sing et al. 2009, Djawe et al. 2012). Most of the studies over the years have been descriptive and did not use sophisticated statistical techniques. Seasonal association with more frequent occurrence of $\mathrm{PcP}$ in the summer has been found in some reports, but overall the results have been inconsistent.

Several studies are of particular interest because they illustrate new concepts relating to the environmental effects on PcP or new ways of studying these effects. A report that analyzed the Multicenter AIDS Cohort Study (MACS) participants found that subjects who developed $\mathrm{PcP}$ as the AIDS defining illness had a significantly higher frequency of upper respiratory illness (URI) before the diagnosis of AIDS than subjects who did not develop PcP (Hoover et al. 1991). The URIs peaked during the cold weather (Jan-Feb) and were followed 4 months later in the warm weather (May-June) by the peak incidence of PcP. Cities that had the highest URIs also had the highest incidence of PcP. Thus, the similar patterns of occurrence of the URIs and PcP raised the possibility of person-to-person transmission of $\mathrm{PcP}$ similar to that of other respiratory pathogens.

Two other reports examined the effects of climate on the occurrence of $P$. jirovecii genotypes and on the mortality from PcP in a large cohort of HIV+ patients in the United Kingdom (Miller et al. 2007, Miller et al. 2010). Data in the genotype study showed that there was significant monthly and seasonal variation in the occurrence of $P$. jirovecii Genotype 2 and with mixed genotypes, but not with Genotypes 1, 3, or 4 (Miller et al. 2007). These results suggested that $P$. jirovecii genotypes may have different physical requirements for organism survival and communicability. The unadjusted analysis in the mortality study found that there was significant seasonal variation in PcP mortality; however, after adjustment for various confounders, this result was no longer statistically significant (Miller et al. 2010). It should be pointed out that mortality is just one end point. Physical requirements for infectivity may be more important for dispersion, transmission and adaptive responses. A pathogen such as Pneumocystis may not want to kill its host, so that would be a positive survival factor, as well.

A fourth study used multiple linear regression techniques for the first time to analyze monthly measurements of climatological factors on the occurrence of PcP in HIV and non- 
HIV patients (Sing et al. 2009). The data showed a significant correlation of PcP with warm weather, but not with wind speeds or rainfall.

A very recent report used a new (case-crossover) experimental design to investigate the environmental risk factor for PcP hospitalizations in HIV patients in San Francisco (Djawe et al. 2012). The results showed that these hospital admissions were significantly more common in the summer than in other seasons. Increases in temperature and $\mathrm{SO}_{2}$ were independently associated with hospital admissions for $\mathrm{PcP}$, but the effects of $\mathrm{SO}_{2}$ were modified by carbon monoxide (CO). This finding was the first time that climatological and air pollutant factors were independent risk factors for PcP hospitalizations. Taken together, these results suggest that the effects of environmental factors on $\mathrm{PcP}$ are more complex than previously realized. Further research is needed to determine how these factors exert their effects and if these effects change in different geographic locations.

\section{Properties of Contagious Infections}

The spread of infection from one person to another is a complex process involving factors such as droplet size, ambient conditions, and host receptivity (Sloan et al. 2011, Musher 2003). One form of spread is by droplet transmission in which respiratory droplets are transmitted from the respiratory tract of one person to the respiratory tract (e.g. nasal mucosa, mouth) of another usually at close distances. Droplets are defined as being $>5 \mu$ in size whereas droplet nuclei are defined as $<5 \mu$ (Musher 2003). The distance droplets can travel in the air is inversely proportional to the droplet size. Bacteria such as Streptococcus pneumonia are spread by moderate to large droplets that only travel a few feet from the infected patient and then fall to the ground (Tang 2009, Eames et al. 2009). In contrast, Mycobacterium tuberculosis is transmitted by droplet nuclei, which can stay suspended in air for a long period of time; thus infection here is transmitted by the airborne route. Some organisms such as influenza can be transmitted by casual contact, droplets, and the airborne route which make them very contagious.

Among other factors that influence transmission of infection is the type of activity of the person who is sick. Activities such as sneezing, coughing, talking, and touching can all transmit influenza infection; thus, teaching practical ways to minimize transmission with these activities are an important part of public health prevention strategies (Siegel et al. 2007). Other variables such as environmental factors (temperature, humidity), social networks, locations (e.g. school, work, home, bar), population characteristics (age, health, occupation, immunization status) influence the transmission of infection (Sloan et al. 2011, Tang 2009).

\section{Environmental Influences on Contagious Respiratory Infections}

Studies of seasonal viruses including influenza, respiratory syncytial virus (RSV), and human rhinovirus (HRV) have provided valuable insights into the occurrence of infection with Pneumocystis and other communicable respiratory pathogens. A recent review article, which was similar to the study about mycoses described above (Panackal 2011), found that the seasonal occurrence of these viruses represents a complex situation involving environmental temperature and humidity; pollution; theoretical mathematics; viral factors 
(antigenic variation); demographics; and human behavior (international travel) (Sloan et al. 2011).

Studies of the seasonal occurrence of respiratory virus infections have been complicated by a dispute over definition or type of humidity (relative vs. absolute humidity) that should be used in the data analysis. Humidity itself is defined as the amount of moisture or water vapor in the air. Relative humidity, which is the percentage of the amount of water that the air can hold at a given temperature, is the type of humidity that meteorologists refer to when discussing and forecasting the weather. Absolute humidity is defined as the actual water vapor content of the air.

An example of this controversy occurred when a guinea pig model was used to analyze the aerosol transmission of different strains of influenza, and the effects of temperature and relative humidity on this transmission (Lowen et al. 2007). Each guinea pig (either infected or naïve animal) was placed in an open cage on a shelf of an environmental chamber with one way air flow in the direction toward the naïve animals. The data showed that low temperature and low relative humidity favored transmission of the influenza virus; these conditions were consistent with the peak occurrence of influenza in people. In contrast, another group of investigators reanalyzed the data in this study using absolute humidity rather than relative humidity. Their results showed absolute humidity was a better measure of influenza virus survival, transmission, and seasonality than relative humidity. Further studies suggested that the relationship between influenza virus survival, transmission, temperature and humidity is more complex than previously thought and is unlikely to be explained by a single factor (Palese and Lowen 2011). These events also emphasize the importance of generating consensus about what specific factors should be analyzed.

\section{Properties of Pneumocystis Cysts}

The factors that affect transmission of Pneumocystis cysts are poorly understood. Published and unpublished studies by our group and others have shown that $P$. carinii and $P$. murina stored at $-80^{\circ} \mathrm{C}$ for weeks to months are able to infect immunosuppressed rats or mice and to be tested in vitro for susceptibility of candidate anti-Pneumocysis drugs (Kaneshiro and Maiorano 1996). A more detailed study examined the effects of eight common disinfectants (70\% ethyl alcohol. $10 \%$ iodoform, $0.5 \%$ hypochlorous acid, two $1 \%$ quarternary ammonium salts, $3 \%$ hydrogen peroxide, sodium chlorite, and $1 \%$ cresol soap) and a control (no disinfectant) preparation on the viability of $P$. murina cysts (Kuramochi et al. 1997). The $P$. murina cysts were incubated with each disinfectant for 10 minutes, washed, and inoculated into C.B-17 scid mice. After 8 weeks, the mice were sacrificed, the lungs were removed and examined for $P$. murina cysts. Mouse lungs treated with 7 of the disinfectants revealed no Pneumocystis cysts, suggesting that they were inactivated or killed by the disinfectants. The control group and group whose cysts were treated with $0.5 \%$ hypochlorous acid had good numbers of cysts. The authors concluded that Pneumocystis cysts are susceptible to most common disinfectants. Since the numbers of mice in each group were small, the results need to be interpreted with caution. 


\section{Communicability of Pneumocystis}

There is abundant evidence of the communicability of Pneumocystis in rodents.

Experimental transmission of Pneumocystis infection has been found by close contact and the airborne route in immunodeficient, immunosuppressed, and normal mice, rats, and other animals (Walzer et al. 1977, Dumoulin et al. 2000, An et al. 2003, Chabé et al. 2004, Linke et al. 2009, Hendley and Weller 1971, Hughes 1982, Hughes et al. 1983, Boylan and Current 1992, Wolff et al. 1993, Hong et al. 1992, Aliouat et al. 1995, Henderson et al. 2011). There have been outbreaks of PcP in immunodeficient rodent colonies (Furuta et al. 1993) and Pneumocystis colonization and transmission of Pneumocystis infection in commercial rodent colonies under strict barrier conditions (Walzer et al. 1989).

The communicability of $P$. jirovecii in humans was initially suggested by outbreaks of PcP in premature, malnourished infants in crowded orphanages during and after World War II (Gadjusek D 1957). In the 1960s and 1970s, there were a few reports of outbreaks or clusters of PcP in immunosuppressed patients. One study reported that over a 3 year period there were 10 cases of PcP in 73 renal transplant patients at the university main teaching hospital, but there were no cases of PcP in 34 renal transplant recipients at the affiliated VA Medical Center (Rifkind et al. 1966). The same surgical staff operated at both institutions and no obvious explanation for the different rates of infection was found. In another report, 10 cases of PcP occurred in children with acute lymphocytic leukemia at a children's hospital over a 10 month period (Ruebush et al. 1978). Members of the hospital staff who had close contact with the PcP patients had significantly higher frequency of elevated antibody titers to a crude Pneumocystis antigen than other hospital staff or parents of the infected patients. This result suggested that exposure to, or transmission of, $P$. jirovecii occurred in the hospital environment. The geographic clusters in Cincinnati and San Francisco described above also raised the possibility of person-to person transmission (Dohn et al. 2000, Morris et al. 2000).

Outbreaks of PcP in immunosuppressed patients over the past several decades have occurred mainly in renal transplant recipients. A recent systematic review analyzed 15 peer-reviewed articles describing 16 outbreaks in about 200 patients since 1980 (de Boer et al. 2011a). Mortality before 1990 was high (38\%) but fell to $13 \%$ over time. No seasonal occurrence or environmental source of $P$. jirovecii was found. Common problems included frequent interpatient contact, a lack of isolation procedures, and a lack of chemoprophylaxis. Genotyping was performed by multilocus sequence typing or by analysis of the internal transcribed spacer (ITS) regions 1 and 2 . The data suggested that most outbreaks were caused by a single or dominant strain of $P$. jirovecii; that person-to-person transmission occurred; and that isolation of PcP patients and chemoprophylaxis should be instituted.

Recent reports by Choukri are of considerable interest because they have developed procedures to detect and quantify viable Pneumocystis organisms in the air of patients or rats with PcP (Choukri et al. 2010). In their first study, air samples from 19 hospitalized patients with PcP were collected using a liquid impactor air sampling device and counted with a quantitative real time PCR assay of the mitochondrial large subunit (mtLSU) of the rRNA gene of $P$. jirovecii. The samples were obtained at distances of $1,3,5$, and 8 meters from the 
bedside. Viable $P$. jirovecii DNA was detected in $15(80 \%)$ of the 19 patients at 1 meter from the patient's head with organism burdens of about $10^{3}$ to $10^{6}$ gene copies $/ \mathrm{m}^{3}$. At 8 meters from the bed, a distance that was outside the room, $P$. jirovecii was detected in 4 of 12 samples. However, $P$. jirovecii DNA was not detected in hospital air far away from the $\mathrm{PcP}$ patients or in air outside the hospital. Thus, there was no evidence of an environmental source of $P$. jirovecii.

The investigators conducted a second study of immunosuppressed rats with PcP (Choukri et al. 2011). P. carinii was detected in exhaled air 1 week after inoculation, reached peak levels at $4-5$ weeks, and then stabilized. $P$. carinii levels in the air also correlated with organisms levels in the lungs. This animal model may be helpful in analyzing the effects of environmental factors on $P$. carinii transmission.

More recent clinical studies have extended these observations further. One report showed that PcP outbreaks at two different renal transplant centers were caused by the same strain of PcP, thus raising the question of increased virulence of this strain (Sassi et al. 2012).

Another publication found evidence that renal transplant patients colonized with $P$. jirovecii may have contributed to the spread of infection in an outbreak of PcP (Le Gal et al. 2012). There is also rising interest in revising the recommendations for PcP chemoprophylaxis (de Boer et al. 2011b), consideration of chemoprophylaxis for colonized individuals (Le Gal et al. 2012), and devoting more attention to PcP in other non-HIV immunosuppressed populations (Coyle et al. 2012).

Taken together, these studies support the idea that $P$. jirovecii infection can be spread from person to person by close contact; support CDC recommendations that patients with active $\mathrm{PcP}$ would be isolated from other immunocompromised (and thus at risk) patients (Siegel et al. 2007); raise the question of whether patients colonized with $P$. jirovecii should be isolated; and may lead to more precise assessments of the risk of jirovecii transmission. As more epidemiological evidence about the transmission of $P$. jirovecii is obtained, this recommendation will need to be re-examined. In addition, the serologic data (described below) showing higher antibody levels in health care workers with patient contact needs further follow-up.

\section{Use of Serology in Pneumocystis Communicability Studies}

Serologic studies of $P$. jirovecii infection have been performed for many years, but were limited in their sensitivity and specificity by the use of crude organism or antigen preparations (Walzer 1999). The development of recombinant antigens has helped investigators to overcome these problems. Over the past decade, our group has used recombinant Msg preparations to develop a serologic test. Three recombinant fragments (MsgA, MsgB, MsgC1) that span the length of Msg were initially developed (Daly et al. 2006). MsgC1, which contains the carboxyl terminus and is the most conserved part of Msg, showed the most promise; thus, 3 variants ( $\mathrm{MsgC} 3, \mathrm{MsgC} 8$, and $\mathrm{MsgC} 9$ ) were developed to better characterize the reactivity of the antibodies (Daly et al. 2006, Walzer et al. 2009, Daly et al. 2009). 
The serologic test has been used to analyze antibody responses in a variety of different populations. A few examples are presented here. In one study, we analyzed serum antibody responses to $\mathrm{MsgC} 1$ to determine if occupational exposure to $P$. jirovecii occurred. The data showed that employees (e.g. physicians, nurses, medical students) who had contact with patients exhibited significantly higher antibody levels to $\mathrm{MsgC} 1$ than employees (e.g. lab assistants, administrative personnel) who did not; also, clinical occupation was an independent predictor of high antibody levels to $\mathrm{MsgC} 1$ (Tipirneni et al. 2009). These findings raised the question of whether healthcare workers with clinical contact may serve as a reservoir for $P$. jirovecii and possibly transmit the infection within the hospital. In other studies, we found that there were geographic differences in antibody levels to the recombinant fragments (Walzer et al. 2009, Daly et al. 2009). A third type of study examined the serologic responses of healthy infants and young children in Chile who were followed for two years (Djawe et al. 2010a). MsgC1 was the best fragment to measure changes in antibody levels in response to clinical infection; however, MsgA, the N-terminus and least conserved fragment, was the best fragment to detect seasonal influences on antibody levels. Finally, we analyzed the serologic responses in our San Francisco HIV patients in the diagnosis of PcP (Djawe et al. 2010b). The data showed that HV patients with PCP developed significantly higher $\operatorname{IgG}$ and $\mathrm{IgM}$ antibody levels to $\mathrm{MsgC} 1$ than patients with other causes of pneumonia at the time of diagnosis (time 0 ) and up to 3-4 weeks thereafter. The positive predictive value (PPV) of the serum IgG antibodies rose from $71.5 \%$ at time 0 to $100 \%$ at $3-4$ weeks; the PPV of serum IgM antibodies rose from $79.3 \%$ at time 0 to $89.8 \%$ at 3-4 weeks. Overall, these studies suggest that $P$. jirovecii serology is a helpful tool in epidemiological, clinical, and ecological studies.

\section{RECOMMENDATIONS FOR FUTURE RESEARCH}

Studies over the past 10-20 years have increased our knowledge of Pneumocystis ecology, but also showed that there is much more to be done. In this section, I have built on these advances and suggested the following areas of investigation:

1. There is a need for population studies patients with $\mathrm{PcP}$ emphasizing geographic clustering, environmental sources of $P$. jirovecii, and the effects of air pollutants.

2. Studies are needed to examine $P$. jirovecii colonization and transmission in inpatient and outpatient settings; to detect and characterize the P. jirovecii transmissible form in the air; to develop more rigorous programs of PcP prevention involving and implementing isolation procedures and chemoprophylaxis to patient populations at risk for PcP.

3. There is a need for animal model studies to define the climatological and air pollution risk factors for PcP, and to detect and characterize the Pneumocystis transmissible form in the air.

4. Studies are needed to determine the effects of climatological and air pollution factors on Pneumocystis itself and its interaction with lung cells.

5. There is a need to develop expertise in the following areas in order to conduct these studies: geography, global positioning system (GPS), lung diseases, specialized 
animal models, air sampling, molecular techniques, infection control, and environmental engineering.

6. The resources are needed to carry out these studies include specialized equipment (e.g. animal exposure chambers), air sampling devices, personnel, space, and new sources of funding (e.g. Environmental Protection Agency, industry, specialized organizations).

\section{PERSONAL RECOLLECTIONS}

I first met Pneumocystis during my second year of medical school (1965-1966). This was also the same year I met my future wife, Kathy. It did not take me long to recognize that Kathy was a very special person in my life, and I remain married to her today. By contrast, my interaction with the mysterious and elusive Pneumocystis led to an extra-marital affair that continues to this day. During my Microbiology and Immunology course, I was fascinated with the studies of investigators such as Robert Good and Charles Janeway who showed that primary immune deficiency diseases could be divided into impaired humoral immunity, which was associated with pyogenic bacterial infections; and impaired cellular immunity, which was characterized by intracellular infections such as tuberculosis. PcP was most commonly associated with severe combined immunodeficiency disease (SCID), which involved T cell and B cell defects (Walzer 1986).

During that year of medical school, I also developed a desire to pursue a career in academic medicine. The ability of physician faculty members such as endocrinologists to show how specific perturbations in endocrine biochemical pathways resulted in specific clinical diseases made a big impression on me. Upon graduation from medical school in 1968, I faced the real possibility of the military draft. During the 1960s all young men, including physicians, faced the military draft. As the Vietnam War increased, the need for more draftees also increased. However, service on active duty for two years in different branches the United States Public Service (USPHS) such as the National Institutes of Health (NIH), Centers for Disease Control (CDC), Federal Prisons, and Indian Health Service was an honorable way for physicians to fulfill their military obligation. Competition for these spots was keen. I was fortunate to be selected as an Epidemic Intelligence Service (EIS) Officer in the Parasitic Disease Branch of CDC and served from 1970 to 1972 after completing part of my medical residency. I spent most of my time working in the Parasitic Disease Drug Service, which through an agreement with the FDA, supplied unlicensed (and thus investigational) drugs to physicians throughout the US to treat serious parasitic infections. Follow-up clinical, demographic, epidemiologic, efficacy and toxicity data were collected. By far the most common drug that we supplied was pentamidine isethionate for the treatment of PcP.

I was fortunate to be the lead author on an article that resulted from this work (Walzer et al. 1974). The article later was designated a "Citation Classic" (Walzer 1986) because it was widely quoted as summarizing the current status in the pre-HIV era.

Upon leaving CDC, I spent the next four years in New York City where I completed training and developed laboratory skills in Infectious Diseases and Immunology at Memorial Sloan- 
Kettering Cancer Center and Rockefeller University. This work resulted in the first use of athymic (nude) mice to show that Pneumocystis infection could be transmitted by close contact and the airborne route (Walzer et al. 1977).

In 1976, I accepted a faculty position in the Division of Infectious Diseases at the University of Kentucky and its affiliated Veterans Affairs Medical Center (VAMC). My wife Kathy and I wanted to leave New York and settle in a less crowded and less expensive area of the country. I was excited by the opportunity to establish my own laboratory and research program. At that time, Pneumocystis had only attracted a few investigators because the organism could not be reliably cultured in vitro; PcP afflicted only specialized populations; and treatment (pentamidine) was toxic. Research interest in Pneumocystis decreased further with the discovery that trimethoprim-sulfamethoxazole, which was a licensed drug already in clinical use, was safe and effective in the treatment and prophylaxis of $\mathrm{PcP}$ (Hughes et al. 1978). Faculty colleagues asked me why I wanted to study such a difficult and relatively and unimportant organism. I wasn't sure how best to answer this question other than to state that I had always been fascinated with this creature and was able to obtain funding for my work.

In the late 1970s, two different events converged to have a major impact on my life. First, there was growing national concern about the plethora of specialists, including Infectious Disease physicians. One well-known leader in academia proclaimed at a national meeting that unless steps were taken to reduce the number of Infectious Disease specialists, we would end up with only enough work to culture each other (Petersdorf 1978). The other event was that I began receiving telephone calls from Infectious Disease colleagues in different parts of the country asking why PcP was suddenly occurring in gay men and intravenous drug users. In retrospect, these cases were the early clinical manifestations of HIV infection in the US population.

In the summer of 1981, I accepted a faculty position at the University of Cincinnati and its affiliated VAMC, and have remained here ever since. Around that time, the first descriptions of the new cases of PcP in gay men were published (Masur et al. 1981). It did not take long to see that this new immune deficiency disorder was going to become a major new medical and public health problem with $\mathrm{PcP}$ as the leading opportunistic infection, and a major cause of death. Interest in my PcP research and funding to support this work increased dramatically. A similar situation later occurred among researchers who toiled for years studying retroviruses before they discovered HIV. Both situations illustrate the importance of investigating what really interests you rather than studying things that might be considered more "relevant."

During the 1980s, I developed a multidisciplinary group in Cincinnati to study Pneumocystis. Dr. Melanie Cushion began as a postdoctoral fellow and progressed to Professor with tenure with international recognition for her research accomplishments, such as leading the effort to sequence the $P$. carinii genome. Dr. James Stringer has made major contributions to our understanding of the molecular genetics of Pneumocystis and its major surface glycoprotein, as well as the taxonomic classification of the organism as a fungus rather than as a protozoan. Dr. Edna Kaneshiro has enhanced our knowledge of Pneumocystis lipids and metabolism. Dr. George Smulian has contributed important insights 
to Pneumocystis molecular biology and Dr. Michael Linke has enhanced our understanding of Pneumocystis immunology and pathogenesis. Dr. Kieran Daly was instrumental in the development of the Msg-based serological ELISA assay. Our Pneumocystis group served as a nidus for collaboration between different departments and colleges at the University of Cincinnati, our VAMC, and the Cincinnati Children's Hospital and Medical Center. We trained numerous graduate students and postdoctoral fellows; worked collaboratively with other groups nationally and internationally to attract new investigators and promote Pneumocystis research; and used conferences such as IWOP and membership on editorial journal boards, professional societies, and government funding agencies to accomplish these goals. This work continues to the present day.

My personal research focused on studies of the immunology, pathogenesis, and treatment of $\mathrm{PcP}$ in animal models. I was interested in applying these results to humans (particularly HIV + patients), but there was a lack of suitable antigens and other reagents. By 2002, my colleagues and I developed recombinant $P$. jirovecii antigens that exhibited promise as reagents to analyze the immune responses in humans. In order to gain more skills in clinical and epidemiological research in humans, I was fortunate to obtain funding for one year (Sept 2005 - Aug 2006) to pursue MSc Epidemiology at the London School of Hygiene and Tropical Medicine (LSHTM). That year was a truly memorable experience. We arrived in London a few weeks after the terrorist bombings of subways and buses. One of these episodes had occurred about 1-2 blocks from our flat. The curriculum at LSHTM was intense and required a lot of study. Since I was twice the age of my classmates, the adjustment to life as a student was a challenge. My classmates came from all over the world, which made for lively discussions. They helped me learn the intricacies of STATA for our statistical classes; in return, I gave them information about life in academia, career choices, and the pros and cons of pursuing further education or training in the USA. In addition, the pubs gave us all a chance to learn about London in a personal way.

Upon return to the USA, I switched the focus of my research to translational and epidemiological research studies. It was gratifying to see that the recombinant Msg fragments we developed proved to be valuable serological reagents in serological studies. In addition, I had my first graduate student who did not pursue a doctoral degree in a basic science. Rather he obtained a PhD in Epidemiology and then joined CDC as an EIS officer.

With the onset of the recession, research funds declined and academic institutions struggled to meet their financial obligations. There was ever increasing pressure on faculty members to bring in funds to support their salaries. Not surprisingly, faculty morale declined. In addition, Kathy and I had to spend increasing time caring for sick, elderly parents who lived far away. By 2011, the problems described above led us to begin to consider retirement. After a lot thought and planning, I decided to retire at the end of March, 2012, which was three months short of my $70^{\text {th }}$ birthday. My colleagues had a wonderful retirement celebration for me with friends coming to Cincinnati from near and far ( e.g. Laurence Huang from the University of California San Francisco and Rob Miller, from University College London). 
I feel truly blessed to have had a long and productive academic career, and also to have been involved with IWOP. I have remained active in my retirement, working part time in our institutional Clinical and Translational Science Award mentoring young investigators and doing a small amount of teaching and clinical work.

\section{Acknowledgments}

This work was supported by the Department of Veterans Affairs; National Institutes of Health Gant R01 HL090335; and an Institutional Clinical and Translational Science Award, NIH/NCATS Grant Number 8UL1TR000077-04. Its contents are solely the responsibility of the authors and do not necessarily represent the official views of the NIH.

\section{LITERATURE CITED}

Aliouat EM, Dei-Cas E, Billaut P, Dujardin L, Camus D. Pneumocystitis carinii organisms from in vitro culture are highly infectious to the nude rat. Parasitol Res. 1995; 81:82-5. [PubMed: 7724517]

An CL, Gigliotti F, Harmsen AG. Exposure of immunocompetent adult mice to Pneumocystis carinii f. sp. muris by cohousing: growth of P. carinii f. sp. muris and host immune response. Infect Immun. 2003; 71:2065-70. [PubMed: 12654827]

Baumgardner DJ, Paretsky DP, Baeseman ZJ, Schreiber A. Effects of season and weather on blastomycosis in dogs: Northern Wisconsin, USA. Med Mycol. 2011; 49:49-55. [PubMed: 20491530]

Bishop LR, Helman D, Kovacs JA. Discordant antibody and cellular responses to Pneumocystis major surface glycoprotein variants in mice. BMC Immunol ul. 2012; 12:13:39.10.1186/1471-2172-13-39

Boylan CJ, Current WL. Improved rat model of Pneumocystis carinii pneumonia: induced laboratory infections in Pneumocystis-free animals. Infect Immun. 1992; 60:1589-97. [PubMed: 1548080]

Casanova-Cardiel L, Leibowitz MJ. Presence of Pneumocystis carinii DNA in pond water. J Eukaryot Microbiol. 1997; 44:28S. [PubMed: 9508416]

Cauchemez S, Bhattarai A, Marchbanks TL, Fagan RP, Ostroff S, Ferguson NM, Swerdlow D. Pennsylvania H1N1 working group. Role of social networks in shaping disease transmission during a community outbreak of 2009 H1N1 pandemic influenza. Proc Natl Acad Sci U S A. 2011; 108:2825-30. [PubMed: 21282645]

Centers for Disease Control and Prevention (CDC). Histoplasmosis outbreak among day camp attendees--Nebraska, June 2012. MMWR Morb Mortal Wkly Rep. 2012; 61:747-8. [PubMed: 22992573]

Chabé M, Dei-Cas E, Creusy C, Fleurisse L, Respaldiza N, Camus D, Durand-Joly I. Immunocompetent hosts as a reservoir of Pneumocystis organisms: histological and rt-PCR data demonstrate active replication. Eur J Clin Microbiol Infect Dis. 2004; 23:89-97. [PubMed: 14712369]

Chagas C. Nova tripanosomiaze humana. Studos sobre a mor-folojia e o ciclo evolutivo do Schistotrypanum cruzi $\mathrm{n}$ g., sp., ajente etiologico de nova entidade morbida do homen. Mem Inst Oswaldo Cruz. 1909; 1:159-218.

Chave JP, David S, Wauters JP, Van Melle G, Francioli P. Transmission of Pneumocystis carinii from AIDS patients to other immunosuppressed patients: a cluster of Pneumocystis carinii pneumonia in renal transplant recipients. AIDS. 1992; 5:927-32. [PubMed: 1777173]

Chang CC, Athan E, Morrissey CO, Slavin MA. Preventing invasive fungal infection during hospital building works. Intern Med J. 2008; 38:538-41. [PubMed: 18588524]

Choukri F, Menotti J, Sarfati C, Lucet JC, Nevez G, Garin YJ, Derouin F, Totet A. Quantification and spread of Pneumocystis jirovecii in the surround air of patients with Pneumocystis pneumonia. Clin Infect Dis. 2010; 51:259-265. [PubMed: 20572759]

Choukri F, Aliouat el M, Menotti J, Totet A, Gantois N, Garin YJ, Bergeron V, Dei-Cas E, Derouin F. Dynamics of Pneumocystis carinii air shedding during experimental pneumocystosis. J Infect Dis. 2011; 203:1333-6. [PubMed: 21372312] 
Coyle PV, McCaughey C, Nager A, McKenna J, O’Neill H, Feeney SA, Fairley D, Watt A, Cox C, Curran T. Rising incidence of Pneumocystis jirovecii pneumonia suggests iatrogenic exposure of immune-compromised patients may be becoming a significant problem. J Med Microbiol. 2012; 61:1009-15. [PubMed: 22516133]

Cushion MT. Are members of the fungal genus Pneumocystis (a) commensals; (b) opportunists; (c) pathogens; or (d) all of the above? PLoS Pathog. 2010; 23:e1001009. [PubMed: 20885786]

Cushion MT, Linke MJ, Ashbaugh A, Sesterhenn T, Collins MS, Lynch K, Brubaker R, Walzer PD. Echinocandin treatment of Pneumocystis pneumonia in rodent models depletes cysts leaving trophic burdens that cannot transmit the infection. PLoS One. 2010; 29:e8524. [PubMed: 20126455]

Daly KR, Koch J, Levin L, Walzer PD. Enzyme-linked immunosorbent assay and serologic responses to Pneumocystis jiroveci. Emerg Infect Dis. 2004; 10:848-854. [PubMed: 15200818]

Daly K, Koch J, Respaldiza N, de la Horra C, Montes-Cano MA, Medrano FJ, Varela JM, Calderon E, Walzer PD. Geographic variation in serological response to recombinant Pneumocystis jirovecii major surface glycoprotein antigens. Clin Microbiol Infect. 2009 Oct; 15(10):937-942. [PubMed: 19416292]

Daly KR, Koch J, Shire NJ, Levin L, Walzer PD. Human immunodeficiency virus-infected patients with prior Pneumocystis pneumonia exhibit increased serologic reactivity to several major surface glycoprotein clones. Clin Vaccine Immunol. 2006 Oct; 13(10):1071-1078. Oct15(10): 1590-1597. [PubMed: 17028210]

Delanoe P, Delanoe M. Sur les rapports des kystes de Carinii di poumon des rats avec le Trypanosoma lewse. CR Hebd Sciences Acad Sci. 1912; 155:658-659.

de Boer MG, de Fijter JW, Kroon FP. Outbreaks and clustering of Pneumocystis pneumonia in kidney transplant recipients: a systematic review. Med Mycol. 2011a; 49:673-680. [PubMed: 21453224]

de Boer MG, Kroon FP, le Cessie S, de Fijter JW, van Dissel JT. Risk factors for Pneumocystis jirovecii pneumonia in kidney transplant recipients and appraisal of strategies for selective use of chemoprophylaxis. Transpl Infect Dis. 2011b; 13:559-69. Oct15(10): 1590-1597. [PubMed: 21689251]

Djawe KP, Daly K, Vargas S, Santolaya ME, Pnoce C, Busmante R, Koch J, Levin L, Walzer PD. Seroepidemiological study of Pneumocystis jirovecii infection in healthy infants in Chile using recombinant fragments of the $P$. jirovecii major surface glycoprotein. Int J Infect Dis. 2010a Dec; 14(12):e10606-6.

Djawe KP, Daly KR, Huang L, Levin L, Koch J, Schwartzman A, Fough S, Roth B, Subramania A, Greieco K, Jarlesdberg L, Walzer PD. Serum antibody levels to the Pneumocystis jirovecii major surface glycoprotein in the diagnosis of $P$. jirovecii pneumonia in HIV+ patients. PloS ONE. 2010b Dec.5(14):e14529.

Djawe K, Levin L, Swartzman A, Fong S, Roth B, Subramanian A, Grieco K, Jarlsberg LG, Miller RF, Huang L, Walzer PD. Effects risk factors for Pneumocystis hospitalizations in HIV patients. Clin Infect Dis. 2012; 56:74-81. [PubMed: 23042978]

Dohn M, White M, Vigdorth E, Hertzberg V, Buncher R, Walzer PD. Geographic clustering of Pneumocystis carinii in HIV patients. Am J Resp Crit Care Med. 2000; 162:1617-1621. [PubMed: 11069785]

Dumoulin A, Mazars E, Seguy N, Gargallo-Viola D, Vargas S, Cailliez JC, Aliouat EM, Wakefield AE, Dei-Cas E. Transmission of Pneumocystis carinii disease from immunocompetent contacts of infected hosts to susceptible hosts. Eur J Clin Microbiol Infect Dis. 2000; 19:671-8. [PubMed: 11057500]

Eames I, Tang JW, Li Y, Wilson P. Airborne transmission of disease in hospitals. J R Soc Interface 2009 Suppl. 2009; 6:S697-702.

Edman JC, Kovacs JA, Masur H, Santi DV, Elwood HJ, Sogin ML. Ribosomal RNA sequence shows Pneumocystis carinii to be a member of the fungi. Nature. 1988; 334:519-22. [PubMed: 2970013]

Furuta T, Fujita M, Mukai R, Sakakibara I, Sata T, Miki K, Hayami M, Kojima S, Yoshikawa Y. Severe pulmonary pneumocystosis in simian acquired immunodeficiency syndrome induced by simian immunodeficiency virus: its characterization by the polymerase-chain-reaction method and 
failure of experimental transmission to immunodeficient animals. Parasitol Res. 1993; 79:624-8. [PubMed: 8295897]

Gadjusek DC. Pneumocystis carinii-etiologic agent of interstitial plasma cell pneumonia of premature and young infants. Pediatrics. 1957; 19:543-565. [PubMed: 13419426]

Gigliotti F, Garvy BA, Haidaris CG, Harmsen AG. Recognition of Pneumocystis carinii antigens by local antibody-secreting cells following resolution of P. carinii pneumonia in mice. J Infect Dis. 1998; 178:235. [PubMed: 9652446]

Gigliotti F, Hughes WT. Passive immunoprophylaxis with specific monoclonal antibody confers partial protection against Pneumocystis carinii pneumonia in animal models. J Clin Invest. 1988; 81:1666-8. [PubMed: 2454947]

Greer A, Ng V, Fisman D. Climate change and infectious diseases in North America: the road ahead. CMAJ. 178:715-22. [PubMed: 18332386]

Henderson KS, Dole V, Parker NJ, Momtsios P, Banu L, Brouillette R, Simon MA, Albers TM, Pritchett-Corning KR, Clifford CB, Shek WR. Pneumocystis carinii causes a distinctive interstitial pneumonia in immunocompetent laboratory rats that had been attributed to "rat respiratory virus". 2011

Hendley JO, Weller TH. Activation and transmission in rats of infection with Pneumocystis. Proc Soc Exp Biol Med. 1971; 137:1401-4. [PubMed: 5316452]

Hong ST, Ryu JS, Chai JY, Lee SH. Transmission modes of Pneumocystis carinii among rats observed by karyotype analysis. Kisaengchunghak Chapchi. 1992; 30:283-8. [PubMed: 1297419]

Hoover DR, Graham NM, Bacellar H, Schrager LK, Kaslow R, Visscher B, Murphy R, Anderson R, Saah A. Epidemiologic patterns of upper respiratory illness and Pneumocystis carinii pneumonia in homosexual men. Am Rev Respir Dis. 1991; 144:756-9. [PubMed: 1928944]

Hughes WT. Natural mode of acquisition for de novo infection with Pneumocystis carinii. J Infect Dis. 1982; 145:842-8. [PubMed: 6979590]

Hughes WT, Bartley DL, Smith BM. Natural source of infection due to Pneumocystis carinii. J Infect Dis. 1983; 147:595. [PubMed: 6601170]

Hughes WT, Feldman S, Chaudhary SC, Ossi MJ, Cox F, Sanyal SK. Comparison of pentamidine isethionate and trimethoprim-sulfamethoxazole in the treatment of Pneumocystis carinii pneumonia. J Pediatr. 1978; 92:285-91. [PubMed: 304478]

Icenhour CR, Rebholz SL, Collins MS, Cushion MT. Widespread occurrence of Pneumocystis carinii in commercial rat colonies detected using targeted PCR and oral swabs. J Clin Microbiol. 2001; 39:3437-41. [PubMed: 11574552]

Kaneshiro ES, Maiorano JN. Survival and infectivity of Pneumocystis carinii outside the mammalian host. J Eukaryot Microbiol. 1996; 43:35S. [PubMed: 8822838]

Keely SP, Stringer JR. Complexity of the MSG gene family of Pneumocystis carinii. BMC Genomics. 2009; 10:367. [PubMed: 19664205]

Kuramochi T, Hioki K, Ito M. Pneumocystis carinii cysts are susceptible to inactivation by chemical disinfectants. Exp Anim. 1997; 46:241-5. [PubMed: 9250487]

Larsen HH, von Linstow ML, Lundgren B, Hogh B, Westh H, Lundgren JD. Primary Pneumocystis infection in infants hospitalized with acute respiratory tract infection. Emerg Infect Dis. 2007; 13:66-72. [PubMed: 17370517]

Le Gal S, Damiani C, Rouillé A, Grall A, Tréguer L, Virmaux M, Moalic E, Quinio D, Moal MC, Berthou C, Saliou P, Le Meur Y, Totet A, Nevez G. A cluster of Pneumocystis infections among renal transplant recipients: molecular evidence of colonized patients as potential infectious sources of Pneumocystis jirovecii. Clin Infect Dis. 2012; 54:e62-71. [PubMed: 22337822]

Light R, Kralt D, Embil JM, Trepman E, Wiebe L, Limerick B, Sarsfield P, Hammond G, Macdonald $\mathrm{K}$. Seasonal variations in the clinical presentation of pulmonary and extrapulmonary blastomycosis. Med Mycol. 2008; 46:835-41. [PubMed: 18651302]

Linke MJ, Ashbaugh AD, Demland JA, Walzer PD. Pneumocystis murina colonization in immunocompetent surface protein A deficient mice following environmental exposure. Resp Res. 2009; 10:10.

Lowen AC, Mubareka S, Steel J, Palese P. Influenza virus transmission is dependent on relative humidity and temperature. PLoS Pathog. 2007; 3:1470-6. [PubMed: 17953482] 
Lubis N, Baylis D, Short A, Stebbing J, Teague A, Portsmouth S, Bower M, Nelson M, Gazzard B. Prospective cohort study showing changes in the monthly incidence of Pneumocystis carinii pneumonia. Postgrad Med J. 2003; 79:164-6. 16. [PubMed: 12697918]

Masur H, Michelis MA, Greene JB, Onorato I, Stouwe RA, Holzman RS, Wormser G, Brettman L, Lange M, Murray HW, Cunningham-Rundles S. An outbreak of community-acquired Pneumocystis carinii pneumonia: initial manifestation of cellular immune dysfunction. N Engl J Med. 1981; 305:1431-8. [PubMed: 6975437]

Miller RF, Evans HE, Copas AJ, Cassell JA. Climate and genotypes of Pneumocystis jirovecii. Clin Microbiol Infect. 2007; 13:445-8. [PubMed: 17359333]

Miller RF, Evans HE, Copas AJ, Huggett JF, Edwards SG, Walzer PD. Seasonal variation in mortality of Pneumocystis jirovecii pneumonia in HIV-infected patients. Int J STD AIDS. 2010; 21:497503. [PubMed: 20852200]

Miller RF, Grant AD, Foley NM. Seasonal variation in presentation of Pneumocystis carinii pneumonia. Lancet. 1992; 339:747-8. [PubMed: 1347618]

Morris A, Norris KA. Colonization by Pneumocystis jirovecii and its role in disease. Clin Microbiol Rev. 2012; 25:297-397. [PubMed: 22491773]

Morris AM, Swanson M, Ha H, Huang L. Geographic distribution of human immunodeficiency virusassociated Pneumocystis carinii pneumonia in San Francisco. Am J Respir Crit Care Med. 2000; 162:1622-6. [PubMed: 11069786]

Musher D. How contagious are common respiratory tract infections? Engl J Med 2003. 2003 Mar 27; 348(13):1256-66.

Navin TR, Rimland D, Lennox JL, Jernigan J, Cetron M, Hightower A, Roberts JM, Kaplan JE. Risk factors for community-acquired pneumonia among persons infected with human immunodeficiency virus. J Infect Dis. 2000; 181:158-64. [PubMed: 10608762]

Olsson M, Lidman C, Latouche S, Björkman A, Roux P, Linder E, Wahlgren M. Identification of Pneumocystis carinii f. sp hominis gene sequences in filtered air in hospital environments. J Clin Microbiol. 1998; 36:1737-40. [PubMed: 9620410]

Palese P, Lowen AC. Transmission of a 2009 pandemic influenza virus shows a sensitivity to temperature and humidity similar to that of an H3N2 seasonal strain. J Virol. 2011; 85:1400-2. [PubMed: 21084485]

Panackal A. Geoclimate climate change and infectious diesases: systemic mycoses. J Earth Sci Climate Change. 2011; 2:1-5.

Panackal AA, Li H, Kontoyiannis DP, Mori M, Perego CA, Boeckh M, Marr KA. Geoclimatic Influences on Invasive Aspergillosis after Hematopoietic Stem Cell Transplantation. Clinical Infectious Diseases. 2010; 50:1588-1597. [PubMed: 20450414]

Peláez T, Muñoz P, Guinea J, Valerio M, Giannella M, Klaassen CH, Bouza E. Outbreak of invasive aspergillosis after major heart surgery caused by spores in the air of the intensive care unit. Clin Infect Dis. 2012; 54:24-31.

Petersdorf RG. The doctors' dilemma. N Engl J Med. 1978; 299:629-634.

Redhead SA, Cushion MT, Frenkel JK, Stringer JR. Pneumocystisand Trypanosoma cruzi: Nomenclature and typifications. J Eukaryot Microbiol. 2006; 53:2-11. [PubMed: 16441572]

Rifkind D, Faris TD, Hill RB. Pneumocystis carinii pneumonia: studies in diagnosis and treatment. Ann Intern Med. 1966; 65:943-956. [PubMed: 5332224]

Rudenko G. African trypanosomes: the genome and adaptations for immune evasion. Essays Biochem. 2011; 51:47-62. [PubMed: 22023441]

Ruebush TK 2nd, Weinstein RA, Baehner RL, Wolff D, Bartlett M, Gonzles-Crussi F, Sulzer AJ, Schultz MG. An outbreak of pneumocystis pneumonia in children with acute lymphocytic leukemia. Am J Dis Child. 1978; 132:143-8. [PubMed: 305199]

Sassi M, Ripamonti C, Mueller NJ, Yazaki H, Kutty G, Ma L, Huber C, Gogineni E, Oka S, Goto N, Fehr T, Gianella S, Konrad R, Sing A, Kovacs JA. Outbreaks of Pneumocystis pneumonia in 2 renal transplant centers linked to a single strain of Pneumocystis: implications for transmission and virulence. Clin Infect Dis. 2012; 54:1437-44. [PubMed: 22431811]

Shaman J, Kohn M. Absolute humidity modulates influenza survival, transmission, and seasonality. Proc Natl Acad Sci U S A. 2009; 106:3243-8. [PubMed: 19204283] 
Shipley TW, Kling HM, Morris A, Patil S, Kristoff J, Guyach SE, Murphy JE, Shao X, Sciurba FC, Rogers RM, Richards T, Thompson P, Montelaro RC, Coxson HO, Hogg JC, Norris KA. Persistent Pneumocystis colonization leads to the development of chronic obstructive pulmonary disease in a nonhuman primate model of AIDS. J Infect Dis. 2010; 202:302-12. [PubMed: 20533880]

Siegel, JD.; Rhinehart, E.; Jackson, M.; Chiarello, L. \& the Healthcare Infection Control Practices Advisory Committee. Guideline for Isolation Precautions: Preventing Transmission of Infectious Agents in Healthcare Settings. Centers for Disease Control and Prevention; 2007.

Sing A, Schmoldt S, Laubender RP, Heesemann J, Sing D, Wildner M. Seasonal variation of Pneumocystis jirovecii infection: analysis of underlying climatic factors. Clin Microbiol Infect. 2009; 15:957-60. [PubMed: 19519848]

Sloan C, Moore ML, Hartart T. Impact of Pollution, Climate, and Socio-demographic factors on spatiotemporal dynamics of seasonal respiratory viruses. Clin Transl Sci. 2011; 4:48-54. [PubMed: 21348956]

Stringer JR. Antigenic variation in Pneumocystis. J Eukaryot Microbiol. 2007; 54:8-13. [PubMed: 17300510]

Stringer SL, Stringer JR, Blase MA, Walzer PD, Cushion MT. Pneumocystis carinii: sequence from ribosomal RNA implies a close relationship with fungi. Exper Parasitol. 1989; 68:450-461. [PubMed: 2470612]

Tamerius JD, Comrie AC. Coccidioidomycosis incidence in Arizona predicted by seasonal precipitation. PLoS One. 2011; 6:e21009. Epub 2011 Jun 20. 10.1371/journal.pone.0021009 [PubMed: 21701590]

Tang JW. The effect of environmental parameters on the survival of airborne infectious agents. J R Soc Interface. 2009; 6(Suppl 6):S737-46. [PubMed: 19773291]

Theus SA, Andrews RP, Steele P, Walzer PD. Adoptive transfer of lymphocytes sensitized to the major surface glycoprotein of Pneumocystis carinii confers protection in the rat. J Clin Invest. 1995; 95:2587-93. [PubMed: 7769101]

Theus SA, Smulian AG, Steele P, Linke MJ, Walzer PD. Immunization with the major surface glycoprotein of Pneumocystis carinii elicits a protective response. Vaccine. 1998; 16:1149-57. [PubMed: 9682373]

Tipirneni R, Daly KR, Jarlsbert LF, Koch J, Swartzman A, Roth BM, Walzer PD, Huang L. Healthcare worker occupation and immune response to Pneumocystis jirovecii. Emerg Infect Dis. 2009 Oct; 15(10):1590-1597. [PubMed: 19861050]

Vargas SL, Hughes WT, Santolaya ME, Ulloa AV, Ponce CA, Cabrera CE, Cumsille F, Gigliotti F. Search for primary infection by Pneumocystis carinii in a cohort of normal, healthy infants. Clin Infect Dis. 2001; 32:855-61. [PubMed: 11247708]

Varela JM, Regordan C, Medrano FJ, Respaldiza N, deLa Horra C, Montes-Cano MA, Calderon EJ. Climatic factors and Pneumocystis jiroveci infection in southern Spain. Clin Microbiol Infect. 2004; 10:770-2. [PubMed: 15301686]

Wakefield AE. DNA sequences identical to Pneumocystis carinii f. sp. carinii and Pneumocystis carinii f. sp. hominis in samples of air spora. J Clin Microbiol. 1996; 34:1754-9. [PubMed: 8784583]

Walzer PD. Citation Classics (Article cited: Pneumocystis carinii pneumonia in the United States: epidemiologic, clinical, and diagnostic features). Current Contents. 1986; 27:15.

Walzer PD. Immunological features of Pneumocystis carinii infection in humans. Clin Diagn Lab Immunol. 1999; 6:14-55. [PubMed: 9874657]

Walzer PD, Djawe K, Levin L, Daly KR, Koch J, Kingsley L, Witt M, Golub ET, Bream JH, Talwo B, Morris A. Long-term serologic responses to the Pneumocystis jirovecii major surface glycoprotein in HIV-positive individuals with and without $P$. jirovecii infection. J Infect Dis. 2009; 199:133544. [PubMed: 19301979]

Walzer PD, Kim CK, Linke MJ, Pogue CL, Huerkamp MJ, Chrisp CE, Lerro AV, Wixson SK, Hall E, Shultz LD. Outbreaks of Pneumocystis carinii pneumonia in colonies of immunodeficient mice. Infect Immun. 1989; 57:62-70. [PubMed: 2642471] 
Walzer PD, Pearl DP, Krogstad DJ, Rawson PG, Schultz MG. Pneumocystis carinii pneumonia in the United States: epidemiologic, clinical and diagnostic features. Ann Intern Med. 1974; 80:83-93. [PubMed: 4589515]

Walzer PD, Schnelle V, Armstrong D, Rosen PP. The nude mouse: a new experimental model for Pneumocystis carinii infection. Science. 1977; 197:177-179. [PubMed: 301657]

Walzer PD, Schultz MG, Western KA, Robbins JB. Pneumocystis carinii pneumonia and primary immune deficiency diseases of infancy and childhood. J Pediatr. 1973; 82:416-422. [PubMed: 4540607]

Walzer, PD.; Smulian, AG. Pneumocystis. In: Mandell, GL.; Bennett, JE.; Dolin, P., editors. Principles and Practice of Infectious Diseases. Elsiever, Inc; Philadelphia: 2010. p. 3377-3391.

Wolff L, Horch S, Gemsa D. The development of Pneumocystis carinii pneumonia in germ-free rats requires immunosuppression and exposure to the Pneumocystis carinii organism. Comparative Immunology, Microbiology and Infectious Diseases. 1993; 16:73-76. 